\title{
Observation of Teaching:
}

\section{Direct vs. Vicarious Experiences}

\begin{abstract}
M M either encourage or require students to observe schools, classrooms, and pupil behavior in conjunction with their professional education courses prior to student teaching.

Such observations usually are limited by insufficient observation stations, space, and facilities to accommodate the increased enrollments in professional education today. Even if such limitations were not present, one might ask whether optimum values can be expected when neither students nor instructors can be sure that the object of the observation will be present at the precise time of the observation.
\end{abstract}

These and other problems associated with direct observations probably can be alleviated by the use of appropriate audio-visual materials. Much has been written about using films and other audio-visual materials to "bring the world" into the classroom. Evidence indicates that when this is properly done increased learning can be expected.

This suggests the question, Can vicarious observational experiences be provided which are as effective as direct observational experiences relative to school situations? If this question can be answered in the affirmative, it can be assumed that the limitations mentioned above could be alleviated. This is the principal problem with which this article is concerned.

\section{Problem}

The investigation was designed to determine whether vicarious observations of educational situations made during the professional training of preservice teachers prior to student teaching were as effective as observations of similar situations made directly.

The vicarious observations were made possible through the use of "film and slide sequences" which presented particular educational principles and concepts deemed pertinent to the basic foundation courses.

The specific objectives of the study were (1) to define unit objectives and formulate concepts in order to develop observational goals for each basic course; (2) to assemble, produce and test suitable audio-visual materials in relation to selected concepts for the three basic courses; and (3) to design and conduct an experiment comparing the effects on teachers in preparation with direct and vicarious observational experiences of classroom and school-community situations.

Dr. Fulton is professor of education and Dr. Rupiper is associate professor of education at the University of Oklahoma, Norman.

The research reported in this article was supported by a grant from the United States Office of Education, Department of Health, Education, and Welfare. 
For a lucid discussion of the meaning of observing and a helpful guide to analyzing, evaluating, and improving the teaching of a lesson, see "The Prospective Teacher as Observer," by Geraldine Murphy, pages 150-156.-EDITORS

\section{Methods and Procedures}

The study was conducted within the framework of the teacher education program at the University of Oklahoma during the year 1960-61. It included three basic courses in professional education required of all students enrolled in the College of Education. These courses were "The School in American Culture," "Human Growth and Development," and "Educational Evaluation and Guidance." Direct observations were made at the university laboratory school and in neighboring communities adjacent to the University.

In an effort to establish observational goals for each basic course in education, a content analysis of the subject matter was made. The course objectives and concepts were delineated and used as bases for developing the observational goals. These goals not only served as reference points for the student during each observation, but also were used as guidelines in selecting and producing film and slide sequences which provided the vicarious materials for observations.

The materials which were selected and/or produced had a direct bearing on a set of observational goals involving specific concepts unique to each professional education course. More than two hundred films were viewed in an effort to identify sequences which best illustrated the final list of objectives and concepts. Once the sequences were identified, they were viewed and evaluated by faculty members responsible for teaching the various courses included in this study. Only those sequences which were considered most illustrative of the behavior situations or community settings pertinent to related objectives and concepts were retained. The resulting selections consisted of fourteen sequences in the area of the school in American culture, twenty-five sequences in the area of human growth and development, and nine sequences in the area of educational evaluation and guidance.

The courses, with an example of a unit, objectives, concepts and illustrations, observational goals, and film sequences are as follows: ${ }^{1}$

\section{"The School in American Culture"}

Unit IV: Welfare Levels, Educational Opportunity, and the School Program.

Objective: To understand the relationship of various economic levels to attitudes toward education, curriculum selection, and other major problems in education.

Concept and Illustration: The concept of the social role of the school will influence the curriculum, atmosphere, discipline, and activities.

To illustrate differences between comprehensive and specialized schools.

To illustrate the normal activities of democratic schools.

Observational Goal: The contrast in different types of schools and their socioeconomic environment, such as the one-room school, the three- and four-room school, the village school, the small consolidated town school, and the large rural consolidated school.

Film Sequences: "School and Community" and "Oklahoma Schools and Communities" (slides-project production).

\section{"Human Growth and Development"}

Unit III: Mental Growth and Development.

I The complete list of units, objectives, concepts and illustrations, observational goals, and films and film references are listed in the final report of the research project. See W. R. Fulton and O. J. Rupiper, Selected Vicarious Experiences versus Direct Observational Experiences of Preservice Teachers in the Foundation Areas of Professional Preparation at the University of Oklahoma. (Norman, Oklahoma: College of Education, University of Oklahoma, 1961). 
Objective: To understand the relation of mental growth to the total development.

Concept and Illustration: The most accurate measurements of intelligence known are test results.

To illustrate types of test items such as sensory and motor performances, analogies, opposites, comprehension questions, vocabulary, similarities and differences, completions, absurdities, deferred memory, memory for meaningful material, and mechanical or rote memory.

Observational Goal: The administration of an individual mental test.

Film Sequence: "Testing Intelligence" and "Problem Solving."

"Educational Evaluation and Guidance"

Unit II: The Function of Evaluation and Guidance.

Objective: To understand the nature and purposes of the role of the teacher in evaluation and guidance.

Concept and Illustration: Value judgments are based on pertinent information obtained through both subjective and objective techniques.

To illustrate subjective techniques of gathering information through anecdotal records and observations.

To illustrate objective techniques of gathering information through teacher-made standardized tests.

Observational Goal: The application of measurement in evaluation.

Film Sequence: "The Evaluation Process."

\section{Experimentation}

The experimental phase of the study was structured to test the null hypothesis concerning differences as they affect student understanding of conceptual principles as a result of different observational techniques. The data used in testing this hypothesis were scores obtained from the administration of an achievement test which consisted primarily of items that were developed and selected according to established criteria (objectives, concepts, and goals) and, insofar as possible, that called for an understanding of concepts pertinent to each basic course.
The sample subjects for the study were selected during the four-day registration period for the fall semester of the 196061 academic year. A random procedure was used so that each student would have an equal chance to be included in any one of the sections, regardless of the time at which he was scheduled to enroll. Approximately forty-five students were enrolled in each section of each of the three basic courses.

Two instructors with relatively comparable qualifications were selected, each to teach two sections of the same course, one section designated as the vicarious observation group and the other as the direct observation group. The designation of the groups was determined by the flip of a coin. Not until the first meeting of the classes did the instructors or the students know in which group they had been placed. After enrollment was completed, no students were permitted to change sections, and no instructors were permitted to change groups.

Each of the three basic education courses thus involved four sections of students, two being designated as vicarious observation groups and two as direct observation groups.

Guided by the specific directions included in the observational goals, members of the direct observation groups made nine thirty-minute observations of actual classroom and school-community situations. Concurrently, members of the other sections, who were also directed by the list of observational goals, participated in nine thirty-minute vicarious observational experiences by viewing "film and slide sequences." These "film and slide sequences" depicted similar educational situations being observed by the direct observation group.

At the beginning of the class sessions, the Cooperative School and College Ability Tests, Form 1C, the Minnesota Teacher Attitude Inventory, Form A, 
the Sims Social Class Identification Occupational Rating Scale, and the achievement test were administered to all students in each section. Hereafter, the standardized tests will be referred to as $S C A T, M T A I$, and $S C I$, respectively. These tests were selected as bases for isolating factors such as scholastic aptitude, attitude toward teaching, and identification with a particular socio-economic level which might bias the results of the study. The results of the initial administration of the achievement tests were used as a measure of initial concept understanding in each of the courses and, of course, provided information common to all students.

The SCAT Quantitative, SCAT Verbal, and $M T A I$ raw scores were converted to percentiles, using appropriate national norms as established by the respective test publishers. These percentiles were transformed to McCall's T-score equivalents. The $S C I$ obtained scores for socioeconomic class identification were used in the original form. In view of the method of construction, the scores on the achievement tests, which were the number of correct responses, were used in raw score form. The scores obtained from the initial administration of the achievement test will hereafter be referred to as the Pre-Test scores.

At the termination of the semester of instruction (during the final examination period), the achievement test was administered again. The scores obtained on this examination were used as the dependent or criterion variable in the final analysis of data. These scores shall hereafter be referred to as the Post-Test scores.

\section{Results}

A $6 \times 6$ correlation matrix was computed for each of the three groups of students, 164 enrolled in "The School in American Culture," 148 in "Human Growth and Development," and 156 in "Educational
Evaluation and Guidance." Data used in these matrices were obtained from the administration of four instruments: $S C A T$, Verbal and Quantitative, $M T A I$, $S C I$, and an achievement test. (See Table I.)

A consistently significant positive correlation was found between the Pre- and Post-Test scores, $r=0.771, r=0.664$, and $r=0.656$ with probabilities less than the 0.01 level of significance for the three courses as listed above respectively. For the same groups statistically significant positive correlations were found between Pre-Test scores and $S C A T$ Verbal scores, $r=0.678, r=0.515$, and $r=0.671$, respectively. These results indicated that intelligence and achievement varied in the same direction for the sample used. Only one significant positive correlation existed between $M T A I$ and Post-Test scores $(r=0.431$, $\mathrm{P}<0.01)$. This occurred in "Educational Evaluation and Guidance." This finding suggested that teacher attitude did not become significant until later in professional training. It appeared that these students who were beginning their professional education work tended toward identification with a single socio-economic stratum, since the coefficients of correlation between $S C I$ scores and scores for the other variables were consistently non-significant for all groups.

Through the use of the multiple regression technique, a single composite score for the five independent variables (all test scores except the Post-Test scores, which was the criterion variable) was computed for each student. This was done for the purpose of permitting maximum utilization of the separate and combined effects of the independent variables. Separate variable coefficients were computed for each course because the concepts for each course were different.

An analysis of covariance was performed on mean achievement scores as 
TABLE I

Matrix of Intercorrelations Between Criterion and Predictor Variables (Read as follows: $\mathrm{X}_{1}=$ Post-Test; $\mathrm{X}_{2}=S C A T$ Verbal; $\mathrm{X}_{3}=S C A T$ Quantitative; $\mathrm{X}_{4}=M T A I ; \mathrm{X}_{5}=S C I ; \mathrm{X}_{6}=$ Pre-Test)

\begin{tabular}{|c|c|c|c|c|c|c|c|c|c|}
\hline Course & Variable & $\mathbf{x}_{1}$ & $\mathrm{X}_{2}$ & $\mathrm{X}_{3}$ & $\mathrm{X}_{4}$ & $\mathrm{X}_{5}$ & $\mathrm{X}_{6}$ & Mean & S.D. \\
\hline $\begin{array}{l}\text { "The School } \\
\text { in American } \\
\text { Culture" } \\
(\mathrm{N}=164)\end{array}$ & $\begin{array}{l}\mathbf{X}_{1} \\
\mathbf{X}_{2} \\
\mathbf{X}_{3} \\
\mathbf{X}_{4} \\
\mathbf{X}_{5} \\
\mathbf{X}_{6}\end{array}$ & 1.000 & $\begin{array}{l}0.663^{\mathrm{a}} \\
1.000\end{array}$ & $\begin{array}{l}0.356^{\mathbf{b}} \\
0.338^{\mathbf{b}} \\
1.000\end{array}$ & $\begin{array}{r}0.188 \\
0.189 \\
-0.089 \\
1.000\end{array}$ & $\begin{array}{r}-0.018 \\
0.032 \\
-0.143 \\
0.093 \\
1.000\end{array}$ & $\begin{array}{r}0.771^{\mathrm{a}} \\
0.678^{\mathrm{a}} \\
0.309^{\mathrm{b}} \\
0.163 \\
-0.024 \\
1.000\end{array}$ & $\begin{array}{l}47.76 \\
52.04 \\
49.94 \\
36.57 \\
22.51 \\
42.64\end{array}$ & $\begin{array}{l}8.252 \\
8.364 \\
8.971 \\
7.190 \\
4.694 \\
7.738\end{array}$ \\
\hline $\begin{array}{l}\text { "Human } \\
\text { Growth and } \\
\text { Development" } \\
(\mathrm{N}=148)\end{array}$ & $\begin{array}{l}\mathrm{X}_{1} \\
\mathrm{X}_{2} \\
\mathrm{X}_{3} \\
\mathrm{X}_{4} \\
\mathrm{X}_{5} \\
\mathrm{X}_{6}\end{array}$ & 1.000 & $\begin{array}{l}0.515^{\mathrm{a}} \\
1.000\end{array}$ & $\begin{array}{l}0.172 \\
0.440^{\mathrm{a}} \\
1.000\end{array}$ & $\begin{array}{l}0.251 \\
0.325^{b} \\
0.169 \\
1.000\end{array}$ & $\begin{array}{r}-0.056 \\
0.003 \\
-0.103 \\
0.075 \\
1.000\end{array}$ & $\begin{array}{r}0.664^{\mathrm{a}} \\
0.515^{\mathrm{a}} \\
0.182 \\
0.283 \\
-0.003 \\
1.000\end{array}$ & $\begin{array}{l}48.74 \\
53.03 \\
50.97 \\
37.78 \\
22.78 \\
39.95\end{array}$ & $\begin{array}{l}6.567 \\
8.474 \\
7.628 \\
6.843 \\
4.890 \\
6.781\end{array}$ \\
\hline $\begin{array}{l}\text { "Educational } \\
\text { Evaluation } \\
\text { and Guidance" } \\
(\mathrm{N}=156)\end{array}$ & $\begin{array}{l}\mathrm{X}_{1} \\
\mathrm{X}_{2} \\
\mathrm{X}_{3} \\
\mathrm{X}_{4} \\
\mathrm{X}_{5} \\
\mathrm{X}_{6}\end{array}$ & 1.000 & $\begin{array}{c}0.582^{\mathrm{a}} \\
1.000\end{array}$ & $\begin{array}{l}0.319^{b} \\
0.280 \\
1.000\end{array}$ & $\begin{array}{l}0.387^{\mathrm{a}} \\
0.374^{\mathrm{a}} \\
0.182 \\
1.000\end{array}$ & $\begin{array}{r}-0.037 \\
0.176 \\
-0.038 \\
0.103 \\
1.000\end{array}$ & $\begin{array}{l}0.656^{\mathrm{a}} \\
0.671^{\mathrm{a}} \\
0.276 \\
0.431^{\mathrm{a}} \\
0.059 \\
1.000\end{array}$ & $\begin{array}{l}48.69 \\
53.76 \\
50.89 \\
42.21 \\
23.69 \\
41.63\end{array}$ & $\begin{array}{l}6.911 \\
8.182 \\
8.509 \\
8.739 \\
5.141 \\
6.800\end{array}$ \\
\hline
\end{tabular}

a Significant at the 0.01 level of significance.

b Significant at the 0.05 level of significance.

measured by the Post-Test for all sections in each course. This technique permitted the adjustment of mean scores by removal of any regression effect of one or more identifiable independent variables. The null hypothesis of no statistically significant difference between mean achievement as indicated by test scores obtained through the measurement of understanding of concepts by students who participated in selected vicarious observational experiences and those who participated in direct observational experiences was tested for each basic foundation course in education. The data are summarized in Tables II, III, and IV.

For "The School in American Culture," the results of the analysis of covariance test of significance showed that the difference between methods of observational experiences was significant with an $F$ ratio of $8.42(\mathrm{P}<0.01)$. The null hypothesis was rejected. It was concluded that students who participated in the vicarious observational experiences demonstrated significantly greater understanding of concepts as determined by analysis of difference between adjusted means than students who participated in direct observational experiences.

For "Human Growth and Development" and "Educational Evaluation and Guidance," the analysis of covariance yieled $F$ ratios of 0.15 and $0.13(P<0.05)$ respectively, between methods. The null hypothesis was not rejected for each of these courses, and it was concluded that students who participated in vicarious observational experiences and direct observational experiences did not differ significantly in mean scores in the understanding of concepts as measured by the achievement Post-Test. However, in 
TABLE II

Summary of Analysis of Covariance for "The Sahool in American Culture"

\begin{tabular}{|c|c|c|c|c|c|c|c|c|}
\hline \multirow{3}{*}{$\begin{array}{l}\text { Source of } \\
\text { Variation }\end{array}$} & \multirow{3}{*}{$\begin{array}{l}\text { Degrees of } \\
\text { Freedom }\end{array}$} & \multicolumn{3}{|c|}{ Sums of Squares and } & \multirow{2}{*}{\multicolumn{3}{|c|}{ Deviation About Regression }} & \multirow{3}{*}{ F-ratio } \\
\hline & & & Products & & & & & \\
\hline & & $\Sigma x^{2}$ & $\Sigma x y$ & $\Sigma y^{2}$ & $\Sigma x^{2}-(\Sigma x y)^{2} / \Sigma y^{2}$ & d.f. & m.s. & \\
\hline (r) Replicates & 40 & 3106.98 & 22.86 .96 & 2341.49 & & & & \\
\hline Between Methods (A) & 1 & 21.23 & -41.26 & 80.22 & & & & \\
\hline Between Teachers (B) & 1 & 204.20 & 176.19 & 152.03 & & & & \\
\hline Interaction $\mathbf{A B}$ & 1 & 15.86 & 10.29 & 6.68 & & & & \\
\hline Error & 120 & 7819.46 & 5346.38 & 5401.16 & 2527.31 & 119 & 21.24 & \\
\hline$A+$ Error & 121 & 7840.69 & 5305.11 & 5481.38 & 2706.17 & 120 & & \\
\hline \multicolumn{5}{|c|}{ Difference for testing among adjusted A-means } & 178.86 & 1 & 178.86 & $8.42^{\circ}$ \\
\hline$B+$ Error & 121 & 8023.66 & 5522.57 & 5553.19 & 2531.54 & 120 & & \\
\hline \multicolumn{5}{|c|}{ Difference for testing among adjusted B-means } & 4.23 & 1 & 4.23 & 0.20 \\
\hline $\mathrm{AB}+$ Error & 121 & 7835.32 & 5356.67 & 5407.84 & 2529.34 & 120 & & \\
\hline \multicolumn{5}{|c|}{ Difference for testing among adjusted AB-effects } & 2.03 & 1 & 2.03 & 30.10 \\
\hline
\end{tabular}

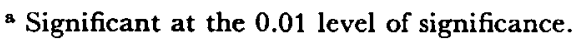

"Human Growth and Development" a statistical significance was found between instructors. Since no statistically significant difference was found between types of observational experiences, it seemed appropriate to accept the null hypothesis in that the significance in mean achievement was due apparently to instructor effect exclusive of method.

For all courses the non-significant interaction values obtained for teacher by method suggested that teachers did not operate any more effectively with one method than the other.

\section{Discussion}

Since "The School in American Culture" is the first course in the professional education sequence, most students enrolled in this course have not had an opportunity to acquire any predisposition toward conventional educational methodology. If this assumption is reasonable, vicarious observational experiences were more successful for the following reasons:

1. The students apparently lacked an orientation to educational situations relating to conceptual principles.

\section{TABLE III}

Summary of Analysis of Covariance for "Human Growth and Development"

\begin{tabular}{|c|c|c|c|c|c|c|c|c|}
\hline \multirow{2}{*}{$\begin{array}{l}\text { Source of } \\
\text { Variation }\end{array}$} & \multirow{2}{*}{$\begin{array}{l}\text { Degrees of } \\
\text { Freedom }\end{array}$} & \multicolumn{3}{|c|}{$\begin{array}{c}\text { Sums of Squares and } \\
\text { Products }\end{array}$} & \multicolumn{3}{|c|}{ Deviation About Regression } & \multirow[t]{2}{*}{ F-ratio } \\
\hline & & $\Sigma \mathbf{x}^{2}$ & $\Sigma x y$ & $\Sigma y^{2}$ & $\Sigma x^{2}-(\Sigma x y)^{2}$ & 2 d.f. & m.s. & \\
\hline (r) Replicates & 36 & 1114.74 & 603.92 & 734.95 & & & & \\
\hline Between Methods (A) & 4) & 8.76 & 13.38 & 20.44 & & & & \\
\hline Between Teachers (B) & B) & 19.70 & -24.15 & 29.61 & & & & \\
\hline Interaction $\mathbf{A B}$ & 1 & 132.43 & 59.03 & 26.31 & & & & \\
\hline Error & 108 & 5106.61 & 2450.77 & 2292.05 & 2486.12 & 107 & 23.23 & \\
\hline$A+$ Error & 109 & 5115.36 & 2464.15 & 2312.49 & 2489.61 & 108 & & \\
\hline \multicolumn{5}{|c|}{ Difference for testing among adjusted A-means } & 3.48 & 1 & 3.48 & 0.15 \\
\hline B + Error & 109 & 5126.31 & 2426.31 & 2321.66 & 2589.99 & 108 & & \\
\hline \multicolumn{5}{|c|}{ Difference for testing among adjusted B-means } & 103.87 & 1 & 103.87 & $4.47^{\mathrm{s}}$ \\
\hline $\mathrm{AB}+$ Error & 109 & 5239.04 & 2509.80 & 2318.36 & 2521.99 & 108 & & \\
\hline \multicolumn{5}{|c|}{ Difference for testing among adjusted AB-effects } & 35.87 & 1 & 35.87 & 1.54 \\
\hline
\end{tabular}

a Significant at the 0.05 level of significance. 
2. The opportunity for observing many of the school-community situations was not available within the immediate confines of the University of Oklahoma.

3. The students enrolled in "The School in American Culture" were just beginning their professional education programs; therefore, they had less experience in directly observing situations relating to conceptual principles than students enrolled in the other two courses.

4. First experiences with direct observation as a means of understanding and reinforcing concepts were frequently bewildering to many students because of the occurrence of unexpected extraneous situations at the time the observation was made.

In view of the results of this study, it would appear that in the first professional education course where observational experiences are required for the purpose of helping students to have a better understanding of concepts pertinent to the course, students would acquire an understanding more efficiently through the use of films, film sequences, and slides. In subsequent courses, the understanding of concepts can be acquired as effectively through vicarious observational experiences as by direct observational experiences.
Because there was a statistically significant difference between the results of the two observation methods in "The School in American Culture" in favor of the vicarious observational experiences, and even though there were no statistically significant differences between the results of the two observation methods in "Human Growth and Development" and "Educational Evaluation and Guidance," it seems reasonable to make the following conclusions:

1. Many of the problems associated with direct observations can be alleviated by use of appropriate audio-visual materials. Nevertheless, the accrediting agencies are currently placing emphasis on more extended direct observational practices in their standards for accreditation. Perhaps more attention should be given to the types, quality, and quantity of audio-visual materials and facilities for their use in relation to observational opportunities.

Such a change of emphasis would provide opportunities for students to observe many more educational situations which might increase both the depth and breadth of their understanding of conceptual principles. Such expansion of observational opportunities could greatly enhance the effectiveness of student

\section{TABLE IV}

Summary of Analysts of Covariance for "Educational Evaluation and Guidance"

\begin{tabular}{|c|c|c|c|c|c|c|c|c|}
\hline \multirow{2}{*}{$\begin{array}{l}\text { Source of } \\
\text { Variation }\end{array}$} & \multirow{2}{*}{$\begin{array}{l}\text { Degrees of } \\
\text { Freedom }\end{array}$} & \multicolumn{3}{|c|}{$\begin{array}{c}\text { Sums of Squares and } \\
\text { Products }\end{array}$} & \multirow{2}{*}{$\begin{array}{l}\text { Deviation About } \\
\Sigma \mathrm{y}^{2}-(\Sigma \mathrm{xy})^{2} / \Sigma \mathrm{y}^{2}\end{array}$} & \multirow{2}{*}{$\begin{array}{l}\text { Regression } \\
2 \quad \text { d.f. }\end{array}$} & \multirow{2}{*}{ m.s. } & \multirow[t]{2}{*}{ F-ratio } \\
\hline & & $\Sigma \mathbf{x}^{2}$ & $\Sigma x y$ & $\Sigma \mathrm{x}^{2}$ & & & & \\
\hline (r) Replicates & 38 & 2119.86 & 888.57 & 813.41 & & & & \\
\hline Between Methods (A) & 1 & 19.39 & 27.99 & 40.41 & & & & \\
\hline Between Teachers (B) & 1 & 205.39 & 86.06 & 36.06 & & & & \\
\hline Interaction $\mathbf{A B}$ & 1 & 8.78 & 13.76 & 21.56 & & & & \\
\hline Error & 114 & 5098.19 & 2709.72 & 2812.41 & 2487.41 & 113 & 22.01 & \\
\hline A + Error & 115 & 5117.58 & 2737.71 & 2852.82 & 2490.34 & 114 & & \\
\hline \multicolumn{5}{|c|}{ Difference for testing among adjusted $\mathrm{A}$-means } & 2.92 & 1 & 2.92 & 0.13 \\
\hline B + Error & 115 & 5303.58 & 2795.78 & 2848.46 & 2559.52 & 114 & & \\
\hline \multicolumn{5}{|c|}{ Difference for testing among adjusted B-means } & 72.11 & 1 & 72.11 & 3.28 \\
\hline $\mathrm{AB}+$ Error & 115 & 5106.97 & 2723.47 & 2833.97 & 2489.68 & 114 & & \\
\hline \multicolumn{5}{|c|}{ Difference for testing among adjusted AB-effects } & 2.27 & 1 & 2.27 & 0.10 \\
\hline
\end{tabular}


teaching experiences and, consequently, improve preservice preparation of teachers in general.

2. Independent educational situational film sequences can be used as media for observational purposes with equal effectiveness with direct observation methods.

This has important implications for film production procedures. Traditionally, the general format of educational films has been patterned after the theatrical film with the usual formal intro- duction, background music, sequential content and continuity, and a unified theme designed to carry the film as a self-entity.

The implication of the findings in this study is that it is feasible, for observational purposes, to produce simple, independent sequences which give a fuller treatment of separate concepts or concept-clusters with emphasis relating specifically to a particular conceptual principle.

\section{No Educational "Elite"}

We believe that there should not be insurmountable barriers to college entrance. As one agency has expressed it, we do not believe in an educational "elite." We believe that students from low-income families should not find it unduly difficult to continue their education. We realize that many students are not sufficiently awakened academically while in high school and thus may not meet the requirements for pursuing a four-year college program. We believe that many of these students, if given an opportunity to make up their educational deficiencies, will develop to the point where their talents can be utilized fully. We recognize further that society's needs call for different kinds and levels of talent. We do not consider that four years of college are always necessary for the optimum development of an individual.

It is partly because of these beliefs that the two-year community college has come into prominence. These colleges have several characteristics: they are located close to the homes of the students who attend; they are relatively inexpensive to attend; and they generally admit anyone who is a high school graduate. In addition to offering the first two years of regular college work, most of them also offer various vocational courses that can be completed in two years or less, thus adding to the diversity of available educational programs beyond high school. They have a very close relationship with the community in which they are located and generally perform a variety of services for the community including the offering of an extensive educational program for adults.

Let me be more specific by describing a somewhat typical community college. It is located in a medium-sized community and has an enrollment of 1,500 full-time day students plus 2,400 students-mostly adults-enrolled in evening courses. It is controlled and supported in part by the community through a local school district although the state also contributes to its support. Students pay a nominal tuition. It admits any high school graduate and any adult over eighteen years of age who is presumed to be capable of profiting from instruction. As a result of these policies its student body has a wide range of abilities and interests and comes from all socioeconomic levels.-Leland $L$. Medsker, "The Community College," Talks on American Education (New York: Bureau of Publications, Teachers College, Columbia University, 1962) p. 73-74. 